\title{
IMPACT OF 'PRESCRIPTION AUDIT \& FEEDBACK' ON PATTERN OF PROPHYLACTIC ANTIMICROBIALS IN CESAREAN SECTION: A COST REDUCTION PERSPECTIVE
}

\author{
MD SHAFIQUL ISLAM, MD SAYEDUR RAHMAN, MIR MISBAHUDDIN
}

Department of Pharmacology, Bangabandhu Sheikh Mujib Medical University, Shahbag, Dhaka, Bangladesh

\begin{abstract}
Cesarean section is a common operative procedure in obstetrics. Prophylactic uses of antimicrobials in different categories of surgeries are irrational in general, which is also observed in cesarean section. Cost of antimicrobial imposes an enormous burden on the patient or the system and considered as an important cost component of cesarean section.
\end{abstract}

A cross-sectional study was conducted from August 2002 to July 2003 in 8 units of the Departments of Gynecology \& Obstetrics of Bangabandhu Sheikh Mujib Medical University, Sir Salimullah Medical College \& Mitford Hospital and Sher-E-Bangla Medical College \& Hospital. Basleline data were collected both retrospective and prospective. After collection of baseline data, result of prescription audit was disseminated among the prescribers through face-to-face discussion and workshop in one unit with particular emphasis on cost perspective.

Quality of record keeping was found satisfactory as there was no significant difference between prospective and retrospective data. Seven different treatment plans were used for prophylaxis. Highest patients were treated with plan-A (46.46\%), followed by plan-B (35.42\%) and lowest with the single dose, plan- $F(1.04 \%)$. Average duration of antimicrobial therapy was highest in plan-D (10.00 \pm 1.55 days) and lowest in plan-F $(6.40 \pm 0.40)$. Average cost of antimicrobial during hospital stay was highest in plan-B $(1497.25 \pm 18.80$ taka) and lowest in plan $-F(90.00 \pm 0.00$ taka). The difference between percentages of patients with different condition of the amniotic membrane receiving same treatment plan was not statistically significant. The difference in patients receiving same treatment plan for different indications was not statistically significant except in treatment plan-F, where patients with relative indications received plan- $F$ significantly higher $(p<0.001)$ than patients presented with absolute indications. Significant relationship was observed with economic status of patient and choice of treatment plan. The average duration of antimicrobial therapy of patients having infection after cesarean section, was $12.16 \pm 0.42$ days and those of patients having no infection after cesarean section, was $7.19 \pm 0.08$ days and this difference was highly significant $(p<0.001)$.

After intervention with 'prescription audit \& feedback', the expensive treatment plan, plan $B$ reduced from $93.33 \%$ to $0.00 \%$ and the difference was highly significant $(p<0.001)$. 'Prescription audit \& feedback' was found to be effective in reducing the infection rate from $16.67 \%$ to $0.00 \%$ and the difference was significant $(p<0.05)$. Average duration of antimicrobial therapy in hospital was reduced from $8.60 \pm 0.22$ days to $7.62 \pm 0.06$ days and the difference was significant $(p<0.05)$. Average cost of antimicrobial therapy was reduced from $1693.11 \pm 30.82$ taka to $511.00 \pm 2.35$ taka and the difference was highly significant $(p<0.001)$.

The initial success of 'prescription audit \& feedback' in improving cost-effective prescribing generated opportunity for partnership between pharmacologist and clinicians in the field of promotion of rational prescribing. The cost-effectiveness of 'prescription audit \& feedback' and its' reproducibility in other clinical situations should be investigated by the future researchers to make this particular intervention acceptable to the policy makers.

(Bangladesh J Physiol Pharmacol 2007; 23(1\&2) : 1-9)

Address of correspondence: Md Shafiqul Islam, Department of Pharmacology, Bangabandhu Sheikh Mujib Medical University, Shahbag, Dhaka, Bangladesh. Email: srkhasru@bsmmu.org

\section{INTRODUCTION}

Cesarean section is a common operative procedure in obstetric practice. The rate of cesarean section is 
increasing steadily during last two decades and varies from country to country ${ }^{1}$. In the United States, incidence of cesarean section was $15 \%$ of all births in tertiary care centers and in European countries it was up to $12.7 \%{ }^{2}$. In the year 2002, cesarean section rate was $18.68 \%$ of all hospital delivery in Bangladesh ${ }^{3}$. In an old study the risk of infection following primary cesarean section was found 10 times than that seen after a vaginal delivery 4 . The rate of infection following cesarean section in highrisk patients averages from $35-40 \% 5$. To prevent the infection, prophylactic use of antimicrobials has got well acceptance $^{2}$. At this juncture, prophylactic means use of antimicrobials pre-operatively, per-operatively or postoperatively before the onset of any infection. That is drugs are used for the purpose of prevention of infection, not for treatment. So in principle, duration of therapy should be short. Antimicrobials administered for more than 48 hours can hardly be called prophylactic. But the decisions regarding choice of drugs, time of starting the first dose and the duration of treatment are yet to be finalized.

Irrational prescribing is a global problem and is also observed in case of prophylactic use of antimicrobials in cesarean section. Almost all studies on the use of prophylactic antimicrobials in cesarean section have demonstrated that the reduction in the incidence of infection is achieved by different drugs and thus unrelated to the drugs, doses and schedules used ${ }^{4-8}$. Unnecessary overuse of antimicrobials, in addition to imposing a burden on the scarce resource, also modifying ecological balance negatively, giving rise to more and more resistant strains of microorganisms ${ }^{9-12}$. Among the identified reasons, lack of confidence regarding sterility of operation theatre and instruments, inadequate information about sensitivity pattern of local infective organisms, over confidence on newer drugs, preference of once daily dosing of newer drugs to multiple dosing of older drugs, affluent patient's preference of costly drugs and above all aggressive sales promotion by the pharmaceutical companies are the meanwhile detected reasons ${ }^{13-14}$. Since 1985, World Health Organization (WHO) and International Network for Rational Use of Drug (INRUD) are trying to develop strategies that will promote rational use of antimicrobials for prophylaxis. Although WHO's Drug Action Program has highlighted the need for action to promote rational drug use, but reports of successful activities in developing countries are few ${ }^{15}$. However, studies revealed that educational intervention and Clinical Practice Guideline considerably improved antimicrobial prescribing 9,16 .

Cost of treatment is an important factor to be considered and is much important in a country like Bangladesh. In Bangladesh, the government is spending only $7 \%$ of total drug expenditure and the rest has to be borne by the individual from his or her own pocket ${ }^{17}$.
Cost of antimicrobial imposes an enormous burden on the patient as well as the health care system. Many researchers considered the economical aspect of antimicrobial therapy as an important cost component of cesarean section ${ }^{18-19}$.

Considering the above understanding, a baseline survey on the present prescribing pattern of antimicrobials prophylaxis in cesarean section was conducted to learn about the situation in Bangladesh. Under the present circumstances, looking for a costeffective alternative antimicrobial for prophylaxis in cesarean section has become the necessity of time and the present study was only a preliminary attempt towards that way.

\section{MATERIALS AND METHODS}

A cross-sectional study was carried out in all units of the Departments of Gynecology and Obstetrics of Bangabandhu Sheikh Mujib Medical University, Sir Salimullah Medical College \& Mitford Hospital (SSMC \& $\mathrm{MH}$ ) and Sher-E-Bangla Medical College \& Hospital (SBMC \& H), which were 8 in total. Among these 8 units, one unit was selected to implement the intervention (prescription audit \& feedback).

\section{Study period}

The study was conducted from August 2002 to July 2003, for a period of one year.

\section{Sources of retrospective data}

Treatment records of cesarean section patients of previous three months kept in the sub-store (record room) of the Gynecology \& Obstetrics ward were utilized as source of data collection.

\section{Sources of current data}

Prospective data were collected from the treatment sheets of the presently admitted patients available on nurse's desk.

\section{Method of data collection}

Information regarding antimicrobial prescribed, duration of antimicrobial therapy, indications for which the patient underwent cesarean section, condition of the amniotic membrane before cesarean section and incidence of infection was recorded in the data compilation form as mentioned in the treatment sheet. Economic status of the patient was recorded from the interview of the patient or her attendant. Cost of antimicrobial was calculated according to the present market price of the prescribed drug.

\section{Sample size}

As recommended in the "How to investigate drug use in health facilities", two sets of data were collected and then combined together for each units ${ }^{20}$. For collection of retrospective data, treatment records of 30 
cases of cesarean section were selected by systematic sampling from the total cesarean section cases of previous three months. For collecting current data, treatment records of the earliest 30 cases of cesarean section were considered from the day of beginning of data collection.

\section{Exclusion criteria}

1. History of amniotic membrane ruptured 12 hours or more before Cesarean section

2. If death of the patient occurred during hospital stay

3. If hospital-stay exceeded 15 days for any reason

4. If patient received antimicrobial for any reason 24 hours or more before the Cesarean section

\section{Variables}

Following variables were measured:

1. Prophylactic antimicrobials prescribed for cesarean section patients.

2. Indications of cesarean sections.

3. Condition of the amniotic membrane before cesarean section.

4. Incidence of any infection.

5. Duration of antimicrobial therapy in hospital.

6. Cost of antimicrobials during hospital stay.

7. Economic status of the patient.

\section{Description of the Intervention}

The intervention (prescription audit \& feedback) was executed in one unit of the studied hospitals. In Bangladesh, there is no Standard Treatment Guideline for prophylactic use of antimicrobial in cesarean section and therefore no 'Gold Standard' was available that can be referred during intervention. Consequently, in this case, attempt was made to disseminate the survey (prescription audit) result to the prescribers and relevant scientific literature was provided to encourage them to select cost-effective treatment option. A part of these were done individually as face-to-face discussion and a part was in-group like workshop. To ensure greater approval of the programs, the senior faculty members of Department of Pharmacology \& Therapeutics of the Sir Salimullah Medical College were involved in developing and executing the feedback and workshop.

Methodology and steps of feedback: According to the recommendations of the working draft of INRUD and manual of WHO/INRUD, prescription audit was done and the results obtained were compiled ${ }^{20-21}$. Then, initially feedback was provided individually through face-to-face discussion and later a workshop was organized to provide feedback in-group as well as to stimulate a consensus among the prescribers:

Step 1: Face-to-face discussion with dissemination of baseline data, provision of printed materials on cesarean section, antimicrobial and cost-effective prescribing.

Step 2: Feedback and group discussion through workshop to identify the reason of present prescribing trend along with dissemination of the study result and information obtained in the first phase of the study.

Step 3: The prescribers discussed the issue and succeed to develop a consensus on reducing the cost of antimicrobial for prophylaxis in Cesarean section. The head of the unit formally declared that consensus after completion of the workshop.

\section{Statistical analysis}

Data were analyzed and compiled manually. Statistical tests of significance between different sets of data were also done manually by $\chi^{2}$ or unpaired "t" test.

\section{RESULT \\ Baseline study on quality of record keeping through comparing prospective and retrospective data}

Table I shows that in retrospective findings, $69.58 \%$ (167/240) cesarean sections were performed with intact amniotic membrane which was $70.42 \%$ (169/240) in the current findings. Cesarean sections were performed with absolute indications was $81.67 \%$ (196/240) and 75.00\% $(180 / 240)$ in retrospective and current findings respectively. In retrospective findings the highest percentage of patients undergoing cesarean section was treated with plan-A, 46.25\% (111/240) it was 46.67\% (112/ 240 ) in current data. Patients treated with treatment plan$B, C, D, E$ and $G$ in retrospective and current baseline findings were respectively $34.17 \%(82 / 240)$ and $36.67 \%$ (88/240), 3.75\% (9/240) and 5\% (12/240), 1.67\% (4/240) and $0.83 \%(2 / 240), 3.75 \%(9 / 240)$ and $1.25 \%(3 / 240)$, $10.41 \%(25 / 240)$ and $7.5 \%(18 / 240)$. In retrospective findings no patient received plan- $F$ while in current findings $2.08 \%$ (5/240) patient were treated with treatment plan-F. Infection rate was $7.08 \%(17 / 240)$ in retrospective findings, which was $6.25 \%$ (15/240) in current findings. Average duration of antimicrobial therapy was (7.51 \pm 0.12 days) and (7.45 \pm 0.10 days $)$ in retrospective and current findings respectively. Average cost of antimicrobial during hospital stay was (896.80 \pm 34.56 taka) and (863.11 \pm 33.25 taka) in retrospective and current findings respectively. All the above differences between retrospective and current findings were statistically insignificant. 
Table I

Comparison between retrospective and prospective data

\begin{tabular}{|c|c|c|c|c|c|}
\hline & & $\begin{array}{l}\text { Retrospective } \\
n=240\end{array}$ & $\begin{array}{l}\text { Prospective } \\
n=240\end{array}$ & $\mathrm{p}$ & Difference \\
\hline Integrityof the & Intact & $69.6 \%(167 / 240)$ & $70.4 \%(169 / 240)$ & $>0.50$ & Not significant \\
\hline $\begin{array}{l}\text { Amniotic } \\
\text { membrane }\end{array}$ & Ruptured & $30.4 \%(73 / 240)$ & $29.6 \%(71 / 240)$ & & \\
\hline \multirow{2}{*}{$\begin{array}{l}\text { Indications of } \\
\text { cesarean } \\
\text { sections }\end{array}$} & Absolute & $81.6 \%(196 / 240)$ & $75.0 \%(180 / 240)$ & \multirow[t]{2}{*}{$>0.05$} & \multirow[t]{2}{*}{ Not significant } \\
\hline & Relative & $18.3 \%(44 / 240)$ & $25.0 \%(60 / 240)$ & & \\
\hline Treatment & $A$ & $46.3 \%(111 / 240)$ & $46.7 \%(112 / 240)$ & $>0.50$ & Not significant \\
\hline \multirow[t]{6}{*}{ plans } & B & $34.2 \%(82 / 240)$ & $36.7 \%(88 / 240)$ & & \\
\hline & $\mathrm{C}$ & $3.8 \%(9 / 240)$ & $5.0 \%(12 / 240)$ & & \\
\hline & $\mathrm{D}$ & $1.7 \%(4 / 240)$ & $0.8 \%(2 / 240)$ & & \\
\hline & $E$ & $3.8 \%(9 / 240)$ & $1.3 \%(3 / 240)$ & & \\
\hline & $\mathrm{F}$ & Nil & $2.1 \%(5 / 240)$ & & \\
\hline & G & $10.4 \%(25 / 240)$ & $7.5 \%(18 / 240)$ & & \\
\hline \multicolumn{2}{|l|}{ Infection rate } & $7.1 \%(17 / 240)$ & $6.3 \%(15 / 240)$ & $>0.50$ & Not significant \\
\hline \multicolumn{2}{|c|}{ Average hospital stay } & $7.5 \pm 0.1$ & $7.5 \pm 0.1$ & $>0.10$ & Not significant \\
\hline \multicolumn{2}{|c|}{ Average treatment cost } & $896.80 \pm 34.56$ & $863.11 \pm 33.25$ & $>0.10$ & Not significant \\
\hline
\end{tabular}

Treatment plan- indicates antimicrobial combination used in different doses, duration and routes.

$\mathrm{A}=$ Cephradine + Metronidazole; $\mathrm{B}=$ Third generation Cephalosporin + Metronidazole

C = Amoxycillin + Metronidazole + Gentamicin; $D=$ Ciprofloxacin + Metronidazole

$\mathrm{E}=$ Cephradine + Metronidazole + Gentamicin; F = Amoxycillin + Metronidazole + Gentamicin (Single dose); G = Others

Table II

Pattern of prophylactic antimicrobials use and their corresponding outcome

\begin{tabular}{lcccc}
\hline $\begin{array}{l}\text { Treatment } \\
\text { Plan }\end{array}$ & $\begin{array}{c}\text { Proportion of } \\
\text { patient received }\end{array}$ & Infection rate & $\begin{array}{c}\text { Average hospital stay } \\
\text { in days (mean } \pm \text { SE) }\end{array}$ & $\begin{array}{c}\text { Total cost of } \\
\text { antimicrobial therapy } \\
\text { in taka (mean } \pm \text { SE) }\end{array}$ \\
\hline A & $46.5 \%(223 / 480)$ & $4.9 \%(11 / 223)$ & $7.4 \pm 0.1$ & $516.60 \pm 6.43$ \\
B & $35.4 \%(170 / 480)$ & $9.4 \%(16 / 170)$ & $8.1 \pm 0.1$ & $1497.25 \pm 18.80$ \\
C & $4.4 \%(21 / 480)$ & $9.5 \%(2 / 21)$ & $7.9 \pm 0.4$ & $611.00 \pm 33.07$ \\
D & $1.3 \%(6 / 480)$ & $33.3 \%(2 / 6)$ & $10.0 \pm 1.6$ & $816.50 \pm 207.16$ \\
E & $2.5 \%(12 / 480)$ & $0.00 \%$ & $6.9 \pm 0.3$ & $667.33 \pm 52.11$ \\
F & $1.0 \%(5 / 480)$ & $0.00 \%$ & $6.4 \pm 0.4$ & $90.00 \pm 0.00$ \\
G & $9.0 \%(43 / 480)$ & $2.3 \%(1 / 43)$ & $6.4 \pm 0.2$ & $615.44 \pm 35.07$ \\
\hline
\end{tabular}




\section{Baseline study on prophylactic antimicrobials and their corresponding outcome}

Table II shows that, $46.46 \%$ (223/480) patients were treated with plan-A, $35.42 \%(170 / 480)$ with plan-B, 4.37 $\%(21 / 480)$ with plan-C, $1.25 \%$ (6/480) with plan-D, 2.50 $\%$ (12/480) with plan-E, $1.04 \%$ (5/480) with plan-F, 8.96 $\%(43 / 480)$ with plan-G. Infection rate was highest in treatment plan-D, $33.33 \%(2 / 6)$ and that was nil in plan$E$ and plan-F. Average duration of antimicrobial therapy was highest in plan-D (10.00 \pm 1.55 days $)$ and lowest in plan-F $(6.40 \pm 0.40)$. Average cost of antimicrobial during hospital stay was highest in plan-B (1497.25 \pm 18.80 taka) and lowest in plan-F (90.00 \pm 0.00 taka).

Baseline study on integrity of the amniotic membrane and choice of treatment plan

Table III shows that among the patients with intact amniotic membrane the highest percentage received treatment plan-A, $46.13 \%(155 / 336)$ and the lowest percentage received treatment plan-D, $1.19 \%(4 / 336)$. Among the patients with ruptured amniotic membrane also the highest percentage received treatment plan-A,
$47.22 \%(68 / 144)$ and none received treatment plan-F. The difference between percentages of patients with different condition of the amniotic membrane receiving same treatment plan was not statistically significant.

\section{Baseline study on indications of cesarean section and choice of treatment plan}

Table IV shows that among the cesarean section cases with absolute indications, the highest percentage of patients were treated with treatment plan-A, $47.34 \%$ $(178 / 367)$ and none was treated with plan-F. In cases with relative indications, also the highest percentage of patients were treated with treatment plan-A, $43.27 \%$ (45/ 104) and the lowest percentage of patients, $4.55 \%$ (2/ 44) were treated with plan-D. The difference in patients receiving same treatment plan for different indications was not statistically significant except in treatment plan$F$, where patients with relative indications received plan$F$ significantly higher $(p<0.001)$ than patients presented with absolute indications.

Table III

Relationship between the condition of the amniotic membrane before cesarean section and treatment plans

\begin{tabular}{|c|c|c|c|c|}
\hline $\begin{array}{l}\text { Treatment } \\
\text { plan }\end{array}$ & $\begin{array}{c}\text { With intact } \\
\text { amniotic membrane } \\
\mathrm{n}=336\end{array}$ & $\begin{array}{c}\text { With ruptured } \\
\text { amniotic membrane } \\
\mathrm{n}=144\end{array}$ & $\mathrm{p}$ & \\
\hline$A$ & $46.1 \%(155 / 336)$ & $47.2 \%(68 / 144)$ & $>0.50$ & Notsignificant \\
\hline B & $35.1 \%(118 / 336)$ & $36.1 \%(52 / 144)$ & $>0.50$ & Not significant \\
\hline C & $3.9 \%(13 / 336)$ & $5.6 \%(8 / 144)$ & $>0.05$ & Not significant \\
\hline $\mathrm{D}$ & $1.2 \%(4 / 336)$ & $1.4 \%(2 / 144)$ & $>0.50$ & Not significant \\
\hline$E$ & $2.1 \%(7 / 336)$ & $3.5 \%(5 / 144)$ & $>0.10$ & Not significant \\
\hline $\mathrm{F}$ & $1.5 \%(5 / 336)$ & $0.00 \%$ & $>0.10$ & Not significant \\
\hline $\mathrm{G}$ & $10.1 \%(34 / 336)$ & $6.3 \%(9 / 144)$ & $>0.10$ & Not significant \\
\hline
\end{tabular}

Table IV

Relationship between indications of cesarean sections and treatment plans

\begin{tabular}{|c|c|c|c|c|}
\hline $\begin{array}{l}\text { Treatment } \\
\text { plan }\end{array}$ & $\begin{array}{c}\text { With absolute } \\
\text { indications } \\
n=376\end{array}$ & $\begin{array}{c}\text { With relative } \\
\text { indications } \\
n=104\end{array}$ & $\mathrm{p}$ & \\
\hline$A$ & $47.4 \%(178 / 376)$ & $43.3 \%(45 / 104)$ & $>0.10$ & Not significant \\
\hline B & $37.0 \%(139 / 376)$ & $29.8 \%(31 / 104)$ & $>0.10$ & Not significant \\
\hline C & $3.7 \%(14 / 376)$ & $6.7 \%(7 / 104)$ & $>0.10$ & Not significant \\
\hline $\mathrm{D}$ & $1.3 \%(5 / 376)$ & $1.0 \%(1 / 104)$ & $>0.50$ & Not significant \\
\hline$E$ & $2.7 \%(10 / 376)$ & $1.9 \%(2 / 104)$ & $>0.50$ & Not significant \\
\hline $\mathrm{F}$ & Nil & 5. $(5 / 104)$ & $<0.001$ & Highly Significant \\
\hline G & $8.0 \%(30 / 376)$ & $12.5 \%(13 / 104)$ & $>0.10$ & Not significant \\
\hline
\end{tabular}




\section{Baseline study on economic status of patient and choice of treatment plan}

Table $\mathbf{V}$ shows that among the patients with economic status-I the highest percentage of them, $60.64 \%(57 / 94)$ were treated with treatment plan-B and among patients with economic status-II and III the highest percentage of them were treated with treatment plan-A, which were $55.13 \%(43 / 78)$ and $61.77 \%(42 / 68)$ respectively. And that relation of economic status with treatment plan was highly significant $(p<0.001)$.

\section{Impact of 'prescription audit \& feedback' on pattern of prophylactic antimicrobial use}

Table VI shows that plan-A was prescribed for 1.67 $\%(1 / 60)$ in baseline, which increased to $80.0 \%(48 / 60)$ after 'prescription audit \& feedback' and the difference was highly significant $(p<0.001)$. The highest proportion, $93.33 \%$ (56/60) patients were treated with treatment plan$\mathrm{B}$ in baseline, which reduced to $0.00 \%(0 / 60)$ after 'prescription audit \& feedback' and the difference was highly significant $(p<0.001)$. Plan-C was prescribed for $5.00 \%(3 / 60)$ patients in baseline, and reduced to $0.00 \%$ after 'prescription audit \& feedback' and the difference was not significant. No patient was treated with plan-E in baseline but after 'prescription audit \& feedback' the rate increased to $20 \%$ (12/60), which was highly significant $(p<0.001)$. No patient was treated with plan-D, F and $G$ in baseline and only $3.33 \%$ (2/60) was treated with plan-G after 'prescription audit \& feedback'. These differences were not significant $(p>0.10)$.

Table V

Relationship between selection of treatment plans with the economic status of patients

\begin{tabular}{|c|c|c|c|c|c|}
\hline $\begin{array}{l}\text { Treatment } \\
\text { plan (total } \\
\text { cost in Taka) }\end{array}$ & $\begin{array}{l}\text { Economic status-I } \\
\qquad \mathrm{n}=94\end{array}$ & $\begin{array}{c}\text { Economic status-II } \\
\qquad \mathrm{n}=78\end{array}$ & $\begin{array}{c}\text { Economic } \\
\text { status-III } \\
n=68\end{array}$ & $p$ & \\
\hline$A(516.60 \pm 6.43)$ & $28.7 \%(27 / 94)$ & $55.1 \%(43 / 78)$ & $61.8 \%(42 / 68)$ & & \\
\hline B $(1497.25 \pm 18.80)$ & $60.6 \%(57 / 94)$ & $23.1 \%(18 / 78)$ & 19.1\% (13/68) & & \\
\hline$C(611.00 \pm 33.07)$ & $7.5 \%(7 / 94)$ & $5.1 \%(4 / 78)$ & $1.5 \%(1 / 68)$ & $<0.001$ & Highly \\
\hline D $(816.50 \pm 207.16)$ & $1.1 \%(1 / 94)$ & $\mathrm{Nil}$ & $1.5 \%(1 / 68)$ & & significant \\
\hline$E(667.33 \pm 52.11)$ & $1.1 \%(1 / 94)$ & Nil & $2.9 \%(2 / 68)$ & & \\
\hline$F(90.00 \pm 0.00)$ & Nil & $2.6 \%(2 / 78)$ & $4.4 \%(3 / 68)$ & & \\
\hline G (615.44 \pm 35.07$)$ & $1.1 \%(1 / 94)$ & $14.1 \%(11 / 78)$ & $8.8 \%(6 / 68)$ & & \\
\hline
\end{tabular}

Economic status- I $\rightarrow$ Monthly income below 5000 taka

Economic status-II $\rightarrow$ Monthly income 5000 - 10000 taka

Economic status-III $\rightarrow$ Monthly income above 10000 taka

Baseline study on infection and duration of antimicrobial therapy

Table VI

Impact of 'prescription audit \& feedback' on pattern of prophylactic antimicrobial use

\begin{tabular}{|c|c|c|c|c|}
\hline Treatment plan & $\begin{array}{c}\text { Baseline } \\
n=60\end{array}$ & $\begin{array}{l}\text { After intervention } \\
\qquad \mathrm{n}=60\end{array}$ & $\mathrm{P}$ & \\
\hline A & $1.7 \%(1 / 60)$ & $80.0 \%(48 / 60)$ & $<0.001$ & Highly significant \\
\hline B & $93.3 \%(56 / 60)$ & $0.0 \%$ & $<0.001$ & Highly significant \\
\hline $\mathrm{C}$ & $5.0 \%(3 / 60)$ & $0.0 \%$ & $>0.50$ & Not significant \\
\hline $\mathrm{D}$ & $0.0 \%$ & $0.0 \%$ & 一- & No difference \\
\hline$E$ & $0.0 \%$ & $20.0 \%(12 / 60)$ & $<0.001$ & Highly significant \\
\hline $\mathrm{F}$ & $0.0 \%$ & $0.0 \%$ & - & No difference \\
\hline $\mathrm{G}$ & $0.0 \%$ & $3.3 \%(2 / 60)$ & $>0.10$ & Not significant \\
\hline
\end{tabular}


Table VII

Impact of 'prescription audit \& feedback' on outcome of prophylactic antimicrobial use

\begin{tabular}{|c|c|c|c|c|}
\hline & $\begin{array}{l}\text { Baseline } \\
\mathrm{n}=60\end{array}$ & $\begin{array}{l}\text { Afterlntervention } \\
\qquad \mathrm{n}=60\end{array}$ & $\mathrm{p}$ & \\
\hline Infection rate(in percentage) & $16.7 \%(10 / 60)$ & $0.0 \%$ & $<0.05$ & Significant \\
\hline $\begin{array}{l}\text { Average duration of antimicrobial therapy } \\
\text { (mean } \pm \text { SE) }\end{array}$ & $8.6 \pm 0.2$ & $7.6 \pm 0.1$ & $<0.05$ & Significant \\
\hline $\begin{array}{l}\text { Average cost of antimicrobial therapy } \\
\text { (mean } \pm \text { SE) }\end{array}$ & $1693.11 \pm 30.82$ & $511.00 \pm 2.35$ & $\begin{array}{l}<0.001 \\
\text { significant }\end{array}$ & Highly \\
\hline
\end{tabular}

Impact of 'prescription audit \& feedback' on outcome of prophylactic antimicrobial use

Table VII shows that the infection rate was $16.67 \%$ (10/60), which reduced to $0.00 \%$ after 'prescription audit $\&$ feedback' and the difference was significant $(p<0.05)$. Average duration of antimicrobial therapy in hospital was $8.60 \pm 0.22$ days in baseline, which reduced to $7.62 \pm$ 0.06 days after 'prescription audit \& feedback' and the difference was significant $(p<0.05)$. Average cost of antimicrobial therapy was $1693.11 \pm 30.82$ taka in baseline, which reduced to $511.00 \pm 2.35$ taka after 'prescription audit \& feedback' and the difference was highly significant $(p<0.001)$.

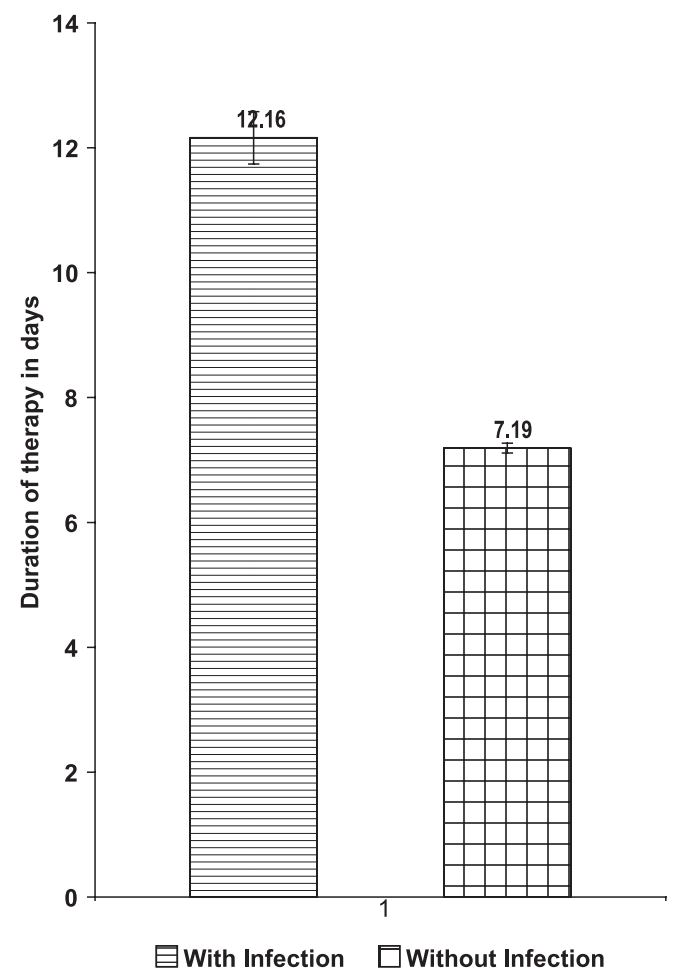

Fig.- 1: Relationship between occurence of infection and average duration of antimicrobial therapy observed in baseline data
Figure I shows that the average duration of antimicrobial therapy of patients having infection after cesarean section, was $12.16 \pm 0.42$ days and those of patients having no infection after cesarean section, was $7.19 \pm 0.08$ days. Statistically this difference was highly significant $(p<0.001)$.

\section{DISCUSSION}

The present study revealed no difference between the prospective with the retrospective sets of data, indicating the satisfactory quality of record keeping of those hospitals. In addition, the finding also reflects that the present prescribing trends in these units were unchanged since last three months. Seven types of treatment plans were prescribed in these units, which perhaps the consequence of absence of Standard Treatment Guideline (STG). In spite of the recommendations to use antimicrobial for a very brief duration of time or single dose, the prescribers used antimicrobial for much longer duration (7.52 \pm 0.10 days).

An attempt was made to identify relationship between the condition of the amniotic membrane before cesarean section and selection of treatment plans. Similar attempt was also made for indications of cesarean section. However, it was observed that these conditions had no influence on the choice of antimicrobial. Though the prescribers often state that every patient is considered individually, nevertheless, that was not reflected in the study findings. In reality, majority or sometime all patients of one unit were treated with the same treatment plan. This trend indicates that perhaps one prescriber, the head of the unit, determines the selection of antimicrobial in a particular unit and the junior doctors and interns of that unit just follow that.

All treatment plans adopted were combination of two or more antimicrobial with Metronidazole in every plan. More than 83 percent patients were treated with Treatment plan-A (46.67\%) and treatment plan-B (36.67\%). All treatment plans of different combinations are in complete disagreement with series of previous observations ${ }^{4,6-7}$, as they mentioned that single 
antimicrobial can significantly reduce the incidence of postoperative febrile morbidity and endometritis in cesarean section. In addition, single agent also found to be effective in treating established endometritis ${ }^{22-23}$.

Significant difference was observed between the outcomes of treatment plan- $A$ and $B$, especially regarding infection rate, average duration of antimicrobial therapy and cost of antimicrobial therapy. Though not significant, but in spite of three folds cost involved with Plan-B, infection rate was yet higher and therefore the duration of antimicrobial therapy as well. This observation supports the previous observation that effect of prophylactic use of antimicrobials in cesarean section happens irrespective of drugs, doses and schedules ${ }^{5}$.

In this study, antimicrobial were continued for the whole period of hospitalization after cesarean section from before, during or immediately after the operation except plan-F. So the mean duration of therapy was at least 7.45 days. This finding indicates that prescribers have not paid attention to those studies, which have shown the effectiveness of short course of prophylactic antimicrobials for cesarean section. The only single dose treatment plan-F was used in one unit of Bangabandhu Sheikh Mujib Medical University and was found superior over other plans regarding infection rate, average duration of antimicrobial therapy and average cost of antimicrobial during hospital stay.

Relationship between selection of drug and economic status of patient was studied and revealed that the poorer patients were being treated with the more expensive treatment plan than the richer group. This perhaps happened because of the perception of the prescriber that poor patients are more prone to infection and therefore require stronger antimicrobials.

In this study, plan- A was most widely practiced $46.46 \%$ (223/480) followed by plan-B, 35.42\% (170/480). Plan-B was found to be the most expensive plan, approximately 1500 taka and that of plan-A was approximately 500 taka. The cheapest treatment plan was plan-F, which was 90 taka for each patient. Treatment cost varied in the same treatment plan from patient to patient due to variation in dose, duration and routes. Primarily infection was identified as the main factor responsible for variation in duration of antimicrobial therapy and consequently cost of antimicrobial therapy. In general, occurrence of infection significantly increased the duration of antimicrobial therapy.

In Bangladesh, rational prescribing in different aspects of health care could not be ensured. Regular drug utilization study in the form of 'prescription audit' is required to achieve this goal. The preliminary success of the 'prescription audit \& feedback' as an intervention to improve cost-effective prescribing might play role of an eye opener. Effectiveness of face-to-face discussion and workshop as a method of feedback has created an opportunity for the partnership between pharmacologist and clinicians in the field of promotion of rational prescribing. The cost-effectiveness of 'prescription audit \& feedback' and its' reproducibility in other clinical situations should be investigated by the future researchers to make this particular intervention acceptable to the policy makers.

\section{ACKNOWLEDGMENT}

The authors gratefully acknowledge the kind cooperation of the teachers, doctors and nurses of the Departments of Obstetrics \& Gynecology of Bangabandhu Sheikh Mujib Medcial University, Sir Salimullah Medical College \& Mitford Hospital and Sher-E-Bangla Medical College \& Hospital. Special thanks to the teachers of the Department of Pharmacology \& Therapeutics of Sir Salimullah Medical College for their generous support particularly during implementation of the intervention.

\section{REFERENCES}

1. Akhter H. Evaluation of hundred cases of cesarean section in Rajshahi Medical College Hospital. Dissertation for FCPS 1999; P-1. BCPS Mohakhali. Dhaka.

2. Coney Ponjola. Operative Obstetrics. In, Jr. William W. Beck, NMS Obstetrics and Gynecology, 3rd edn. Philadelphia, Pennsylvania, Harwal Publishing, 1993; 177-79.

3. Voice of UMIS, Issue 2, April, 2003,UMIS, DGHS, Dhaka, Bangladesh.

4. Kreutner AK, Bene VED, Delamar D, Bodden JL, Loadholt $\mathrm{CB}$. Perioperative Cephalosporin prophylaxis in cesarean section: Effect on endometritis in the high-risk patient. Am J Obstet Gynecol 1979; 134: 925-33.

5. Poggi S B H \& Kapernick P S. Postpartum hemorrhage \& the abnormal puerperium. In DeCherney A H, Nathan L. Current Obstetric \& Gynecologic Diagnosis \& Treatment, 9th Ed. New York, Lange Medical Books/ McGraw-Hill, 2003 ; 531-52.

6. Begum A. A study of metronidazole prophylaxis in obstetrical and gynecological surgery. Dissertation for FCPS 1981; P-119. BCPS Mohakhali. Dhaka.

7. Gall SA. The efficacy of prophylactic antibiotics in cesarean section. Am J Obstet Gynecol 1979; 134: 506-11.

8. Rizk D E E, Nsanze H, Mabrouk MH, Mustafa N, Thomas L, Kumar M. Systemic antibiotic prophylaxis in elective cesarean delivery. Int J Gynecol Obstet 1998; 61:245 -51.

9. Williams JD. Antibiotic guidelines. British Medical Journal 1984; 288(6414): 343-44.

10. Ballow $\mathrm{CH}$, Schentag JJ. Trends in antibiotic utilization and bacterial resistance. Report of the national nosocomial resistance surveillance group. Diagon Microbiol Infect Dis 1992;15: 37S-42S. 
11. ACOG educational bulletin. Antibiotics and gynecologic infections. International Journal of Gynecology \& Obstetrics June 1997; 58: 333-340.

12. Gibbs RS. Antimicrobial chemotherapy. In, DeCherney A H., Nathan L. Current Obstetric \& Gynecologic Diagnosis \& Treatment, 9th edn. New York, Lange Medical Books/ McGraw-Hill, 2003 ; 751-66.

13. Kharazmi A. Iran: A snapshot. Danish Medical Bulletin 1984;31(1): 31.

14. Personal communication. Discussion, with Associate Prof. Dr. Fatema Begum. SSMC \& MH. Dhaka, 2003.

15. Laing RO. Rational drug use: an unsolved problem. Tropical Doctor 1990; 20: 101-3.

16. Lubimova AV, Stolista AA, Rybalkina TV, Maslova SP, Balukova NA, Brown SM, Grable I, Romanova TO, Rourke EJO. Quality improvement intervention improved perioperative antibiotic prophylaxis in cesarean section in Russia.

17. Rabbani G, Hossain MS, Islam AKMT. Health care expenditure in Bangladesh. In, Health situation and health care expenditures in Bangladesh, Bangladesh Bureau of Statisitics, Dhaka, April 1999
18. Stone H H, Haney B B, Kolb L D, Geheber C E, Hooper C A. Prophylactic and preventive antibiotic therapy: Timing, Duration and Economics. Annals of surgery 1979;189(6): 691-98.

19. Anonymous. Measuring the impact of the restricted drug formulary. Editorial. Pharmaceut. Med. 1987; 1: 255-58.

20. WHO. How to investigate drug use in health facilities. Geneva: World Health Organization; 1993. WHO/DAP/ 93.1.

21. Arhinful DK, Das AM, Hadiyono JP, Heggenhougen $\mathrm{K}$, Higginbotham N, Iyun FB, Quick J, Degnan DR. How to use applied qualitative methods to design drug use interventions. INRUD social scientist working group. December, 1996.

22. Cabbad M, Sijin O, Minkoff H. Short course of antibiotics for post-cesarean section endometritis. Am J Obstet Gynecol 1987; 157:908-9

23. Sorrell T C, Marshall J R, Yoshimori R, Chow A W. Antimicrobial therapy of postpartum endomyometritisProspective, randomized trial of mezlocillin versus ampicillin. Am J Obstet Gynecol 1981; 141: 246-51. 